\author{
Tomaž Jurca
}

\title{
OB SLOVENSKEM PREVODU DOPISOV PAPEŠKEGA TAJNIKA PETRA PAVLA VERGERIJA MLAJŠEGA
}

Vergerij ml., Peter Pavel. 2018. Dopisi papeškega tajnika. Actionis duae Secretarii Pontificii. Življenja in dela XVI, Kulturnozgodovinske študije 3. Ur. Matej Hribršek. Kritično izdajo pripravil, prevedel in spremna besedila napisal Gregor Pobežin. Ljubljana: Založba ZRC. 208 strani.

Ime Petra Pavla Vergerija mlajšega, pri nas poznanega predvsem kot Trubarjevega sodelavca, je nedavno spet pritegnilo nekaj pozornosti. Dobili smo namreč slovenski prevod enega njegovih polemičnih spisov, kar je ob vsesplošnem pomanjkanju tovrstnih knjižnih izdaj pri nas vsekakor pomemben dogodek. Povod za prevod dela Actiones duae secretarii pontificii, ki je z naslovom Dopisi papeškega tajnika (Vergerij ml. [1556] 2018) letos izšel pri založbi ZRC SAZU, je slovenski nakup Vergerijevega dela, zasnovanega kmalu po njegovi selitvi iz Švice na Würtemberško. Prvo izdajo knjige, ki je izšla pri tiskarju Oporinu v Baslu leta 1556, je namreč kupil Oddelek za domoznanstvo in knjižno dediščino Knjižnice Srečka Vilharja v Kopru in s tem poleg prevoda spodbudil tudi nov val razprav o tej zanimivi osebnosti. O življenju cerkvenega diplomata, koprskega škofa in verskega spreobrnjenca ter njegovih zaslugah za nastanek prvih slovenskih knjig je bilo napisanega že precej, ${ }^{1}$

1 V reviji Stati inu obstati gl. predvsem članka Cavazze: »'Nenavadna osebnost': Profil Petra Pavla Vergerija« (Cavazza 2013); »Bonomo, Vergerij, Trubar« (Cavazza 2007); tudi Tomaž Jurca: »Inkvizitorjem po Italiji - Vergerijeva polemika proti piscem rimskega seznama prepovedanih knjig iz leta 1559« (Jurca 2016). 
manj pozornosti pa so domači in tuji strokovnjaki posvetili njegovim delom. Tudi roman Fulvia Tomizze, ${ }^{2}$ ki je nedavno izšel v slovenskem prevodu, skorajda pikolovsko preučuje predvsem Vergerijevo biografijo in njegovo zavito življenjsko zgodbo, razmeroma malo prostora pa nameni njegovemu obsežnemu opusu najrazličnejših spisov. K tovrstnemu zapostavljanju Vergerijevih del so bržkone prispevala nenaklonjena mnenja njegovih sodobnikov kot tudi ocena nekaterih italijanskih zgodovinarjev, ${ }^{3}$ spričo katere se je njegovih knjižic prijel sloves prepirljivosti, površnosti in teološke plitvosti. Vergerij resda ni slovel po poglobljenih teoloških razpravah, bil pa je izobraženec in humanist, čigar pisanje velja obravnavati predvsem $v$ kontekstu protestantske propagande in raznovrstnih ter nadvse domiselnih orodij, ki jih je razvil za ta namen.

$\mathrm{V}$ tej luči je slovenski prevod sicer manj poznanega, a zato nič manj zanimivega Vergerijevega dela, ki ga je iz latinščine poslovenil dr. Gregor Pobežin, še toliko dragocnejši. Še posebej zato, ker gre za enega prvih strnjenih prevodov in podrobnejših tematizacij kakega od Vergerijevih del v slovenskem jeziku.

Prvi izdaji Dopisov papeškega tajnika iz leta 1556, ki vsebuje dva spisa, je še za časa avtorjevega življenja sledilo nekaj ponatisov, k tistemu iz leta 1559 pa je Vergerij dodal še tretji spis, ki pomensko dopolnjuje prva dva. Tudi tega si lahko kmalu obetamo v slovenščini. Razprave povzemajo nekatera Vergerijeva razmišljanja in ugotovitve o tridentinskem koncilu, ki jih v svojem nagovoru poglavarju Rimske cerkve bralcu posreduje neimenovani papeški tajnik. Gre za bistroumno protestantsko invektivo z elementi psihološke parodije na račun papeža in akterjev cerkvenega zbora, v kateri so zaznavni tako vplivi Erazmovih satiričnih dialogov kot grmenje Danteja in humanističnih kanclerjev florentinske republike. V Vergerijevi izredni knjižni produkciji, ki vsebuje več kot 180 naslovov, zavzema tridentinski koncil vseskozi pomembno mesto, saj mu je Koprčan posvetil vrsto različnih knjižic, ki črpajo predvsem iz njego-

2 Zlo pride s severa (Tomizza [1984] 2015). Gl. tudi Marko Kerševan: »Peter Pavel Vergerij (1489-1565) in Fulvio Tomizza« (Kerševan 2015).

3 Gl. predvsem Eretici italiani del Cinquecento (Cantimori 1992). 
vih bogatih diplomatskih izkušenj, poznavanja zgodovine in zmožnosti pridobivanja ter širjenja zaupnih cerkvenih dokumentov.

\section{Vergerij in tridentinski koncil}

Cerkveni zbor, ki bi lahko preprečil razkol v zahodnem krščanstvu, je bil ena glavnih Vergerijevih skrbi že v času njegove kariere cerkvenega diplomata. V svoji drugi nunciaturi med letoma 1535 in 1536 je v službi Pavla III. skušal kneze severnih dežel prepričati, da ne bi nasprotovali sklicu koncila zunaj nemških meja in pristali na zbor v Mantovi. Čeprav tedaj še ni bil naklonjen protestantizmu, katerega je imel priložnost pobližje spoznati v nemških deželah, je Vergerij že začel razmišljati o reformi cerkve. Ta razmišljanja je poglobil v času po imenovanju za koprskega škofa, ki ga je najprej izkoristil za potovanja po Italiji in utrjevanje stikov $\mathrm{z}$ uglednimi italijanskimi knezi in prelati. Zavoljo svojih srečanj s protestantskimi teologi v Wormsu in Regensburgu, kjer se je med letoma 1540 in 1541 mudil kot zastopnik francoskega kralja Franca I., je kmalu vzbudil sume papeških poslancev, postopno pa ga je od Rima oddaljilo tudi delovanje v domači škofiji, kjer se je pri svojih poskusih uvajanja reforme sprl z domačo duhovščino. Prav ta je v veliki meri prispevala, da so ravno $v$ času začetka prvega zasedanja tridentinskega koncila proti Vergeriju sprožili inkvizicijski postopek. Zaradi omenjenih težav mu je bilo sodelovanje na zboru, ki se ga je skušal leta 1546 udeležiti kar dvakrat, onemogočeno. Verjetno ni zanemarljivo dejstvo, da mu pri teh poskusih ni pomagal niti reformam sicer naklonjeni kardinal Reginald Pole, ki je bil med papeškimi legati in je bil pred tem Vergeriju vseskozi v oporo. Tudi spričo omenjenih razočaranj, povezanih $\mathrm{z}$ ravnanji mnogih italijanskih prelatov, je Vergerij začel resneje razmišljati o smiselnosti zbora. Prav t. i. nikodemizem visokih italijanskih klerikov, ljudi, ki so spoznali luč evangelija, a se ji zaradi svojih udobnih služb niso odločili slediti, je bil eden pomembnejših dejavnikov, ki so ga sčasoma odvrnili od koncila. 
Odtod tudi zasuk v njegovem pisanju, ki je konec štiridesetih let 16 . stoletja še naklonjeno zboru, kar je razvidno iz zapisa v njegovem prvem posegu proti seznamu prepovedanih knjig. V svojem komentarju k seznamu Giovannija della Case tako piše, da lahko "svoboden krščanski koncil s svojo veljavo reši zagate, ki so se porodile v Cerkvi«. S porazom reformam naklonjenega Polea na konklavu in izvolitvijo Julija III. leta 1550, ki ga je poleg vmešavanja evropskih sil zaznamovalo tudi podtalno delovanje Svetega oficija, pa je začel Vergerij resno dvomiti, da bi novi papež lahko sklical »svoboden« koncil. Nad Rimom se je dvigala tudi mračna senca Gian Pietra Carafe, kasnejšega Pavla IV., ki je s pomočjo inkvizicije sčasoma prevzel nadzor nad mehanizmom papeških volitev in $\mathrm{z}$ različnimi metodami pritiskal na "problematične« prelate. Čeprav je Julij skušal vsaj delno zajeziti Carafovo ofenzivo proti spiritualom, je bil leta 1550 dobršen del Vergerijeve polemične dejavnosti v izgnanstvu že naperjen proti novemu papežu. Tako je od njegove izvolitve do zaključka drugega zasedanja koncila leta aprila leta 1552 dal natisniti vrsto spisov, ki jih Hubert označuje celo za ključno fazo njegove propagandne dejavnosti. Na to plodovito obdobje se pomensko navezujejo tudi Dopisi papeškega tajnika, zato se mu velja posvetiti nekoliko podrobneje.

Vergerij novembra 1550 v spisu z naslovom Dé portamenti di papa Giulio III, naslovljenem na angleškega kralja Edvarda VI., že razglablja, ali bi lahko Karel V. in ostali vladarji sploh preprečili "papeški« koncil in tako spodbudili k prevzemu pobude tiste mlačne italijanske prelate, »ki posnemajo Nikodema«. Ob sklicu drugega zasedanja, ki ga je papež ob Karlovi podpori razglasil z odlokom Bulla reductionis, je lahko Vergerij zgolj upal na čim slabšo udeležbo in za zgled postavil celo francoske prelate, ki so se obiska vzdržali. S tem namenom je dal najprej natisniti nekakšno parodijo bule, ki je poleg izvirnega besedila dokumenta vsebovala tudi komentar, pripisan koprskemu sorodniku Ottonellu Vidi. Pogosto uporabljeno orodje Vergerijeve propagande je bila namreč tudi izdaja avtentičnih cerkvenih dokumentov, pospremljenih s polemičnimi komentarji. Spomladi leta 1551 je Vergerij objavil nekoliko obsežnejšo zbirko različnih dokumentov in spisov z latinskim komentarjem in pomenljivim naslovom Concilium Tridentinum fugiendum esse 
omnibus piis (»Tridentinskemu koncilu bi se morali ogniti vsi pobožni ljudje«). V njej je med drugim zbral pričevanja o tem, kako so z drugače mislečimi ravnali na prejšnjih koncilih, ter opomnil na smrt Jana Husa. Nadvse domiseln je njegov literarni dodatek, Bracciolinijev opis mučenja in smrti Hieronima iz Prage, ki se je, podobno kot Hus, opiral na cesarsko zagotovilo prostega prehoda. Zbirka, ki je bila toplo sprejeta predvsem v protestantskem svetu, je zastavljena kot opozorilo vsem, ki bi svojo usodo zaupali papežu in se preveč zanašali na cesarsko zaščito.

Bolj poglobljena tovrstna dela pa je Vergerij napisal v italijanščini, saj je imel obveščanje sonarodnjakov v domovini vseskozi za prednostno nalogo svoje propagande. Tu velja omeniti predvsem delo Sei dialogi ne quali diffusamente si ragiona del concilio di Trento, ki je anonimno in brez vseh podatkov o izdaji izšlo začetek leta 1552, skoraj zagotovo pri Landolfiju v Poschiavu. Tokrat se je Vergerij odločil za obliko dialoga. Delo je zanimivo predvsem zato, ker v njem poleg literarnih likov Malkolfa in Laktancija nastopata tudi resnični osebi, škofa Soranzo in Nacchianti. Omenjenima škofoma Vergerij zelo svobodno polaga v usta besede, s katerimi skušata prepričati neimenovanega italijanskega prelata, da se ne bi udeležil koncila. Pri tem se opirata na izkušnje s prvega zasedanja, kjer sta zaradi zagovarjanja svojih stališč imela nemalo težav. Soranzo, ki se je med svojo kratkotrajno udeležbo na zboru uprl odloku o opravičenju, je pri tem še posebej odločen, saj pravi, da bi bilo »treba razpustiti ta koncil, poln prevar, da ne bi mogel škodovati božji slavi in miru med krščanskimi ljudstvi«.

Vergerij je Soranzu tako pripisal dokaj težke besede, sploh, če upoštevamo, da je omenjeni v tistem času še opravljal škofovsko službo in imel celo težave $z$ inkvizicijo. Še več, zaradi suma krivoverstva so ga konec marca 1551 za krajši čas zaprli v Castel Sant' Angelo, kjer je preklical svoje prejšnje trditve, da bi se opral krivde. Seveda je bil Vergerij s tem seznanjen, kot je verjetno tudi predvideval, da bodo beneška vlada in dobra poznanstva Soranza obvarovala hujše kazni. Spričo tega se lahko vprašamo, kaj je bil pravzaprav namen tovrstnega pisanja. Bolj kot namerno škodovanje italijanskim prelatom iz vrst spiritualov bi v tem primeru šlo lahko za opozorilo ali celo grožnjo, naj glede koncila in prek- 
licev ravnajo previdno, saj ima o njih precej podatkov pa tudi sredstvo, da jih učinkovito razširi. Dialog, v katerem nastopajo tudi resnične in še živeče osebnosti tistega časa, je vsekakor eno od zanimivejših in hkrati nevarnejših orodij Vergerijeve propagande.

Drugega zasedanja koncila, ki je trajalo razmeroma kratek čas, so se, za razliko od prvega, v večjem številu udeležili tudi škofje s cesarskega ozemlja in poslanci mnogih protestantskih knezov, a njihovih zahtev, ki so se navezovale predvsem na papeško oblast, niso uslišali. Julij je med drugim potrdil tudi odlok o transsubstanciaciji, ki duhovniku daje moč, da med obredom evharistije spremeni vino in kruh v Jezusovo kri in telo, ter poslal jasno sporočilo protestantom o možnostih sprave glede doktrinarnih vprašanj. Koncil je postal tista "pošast ", kot ga imenuje Vergerij v Šestih dialogih, proti kateri se ni upal vzdigniti noben italijanski kardinal ali država.

$\mathrm{V}$ času po koncu drugega zasedanja tridentinskega koncila je bilo Vergerijevo stališče glede zbora popolnoma jasno. Njegovo razmišljanje glede tega nemara najbolje povzema knjižica, izdana leta 1553, torej kako leto pred nastankom Dopisov papeškega tajnika, z razširjenim naslovom ene njegovih prejšnjih zbirk: Concilium non modo Tridentinum, sed omne papisticum perpetuo fugiendum esse omnibus piis (»Vsi pobožni ljudje bi se morali vobče ogibati vsem papeškim koncilom, ne samo tridentinskemu«). Ozračje, v katerem so nastajali Dopisi, je tako že zaznamoval dvig »tiranskega " papeža in ko se je Carafa ob pomoči Svetega oficija leta 1555 tudi sam povzpel na papeški prestol, je politika inkvizicije postala tudi uradna politika Cerkve. Možnosti, da koncil ne bi bil papeški, kot je tožil Vergerij, v tistem času pravzaprav ni bilo več.

\section{Dopisi papeškega tajnika}

Dopisi papeškega tajnika so nastali kmalu po Vergerijevi selitvi iz Graubündna na Würtenberško, kjer je ta nadaljeval s svojo silovito knjižno dejavnostjo v italijanskem in latinskem jeziku. Delo je bilo verjetno prvič natisnjeno leta 1556, njegova zasnova pa je vsaj kako leto starejša in 
sega nemara celo v zadnje mesece Julijevega pontifikata, kar razkrivajo tudi Vergerijeva pisma Bullingerju. Ta čas nastanka je skladnejši tudi s samo vsebino dela, ki skuša papeža odvrniti od misli na ponoven sklic koncila, saj je znano, da je bil Pavel IV. zboru že od samega začetka nenaklonjen. Kaže, da je končno besedilo izdaje iz leta 1556 Vergerij oblikoval malo pred tiskom in ga namenil Pavlu. V tej luči vsebina dela zaživi predvsem kot subtilni posmeh in ironični pozdrav novemu papežu, katerega namen je prej psihološka igra kot pa resnično prepričevanje. Delo se tako izkaže za zanimivo mešanico invektive, ki ima v italijanski književnosti bogato zgodovino, in protestantske propagande, prežete z Vergeriju lastno ostrino, satirično mislijo in odlično informiranostjo.

Prva razprava nosi naslov Ali naj papež Pavel IV. razmisli o ponovnem sklicu Tridentinskega koncila, z ironičnim pripisom »Veliko je namreč upanje, da bo prišlo do miru« na naslovni strani. Vergerij se tako postavi v dobro poznano vlogo papeževega tajnika, ki skuša v zaupnem dopisu svetega očeta prepričati v nesmiselnost ponovnega sklica zbora. Protestantski pozivi k univerzalnem, svobodnem in krščanskem koncilu, na katerem bi kristjani iz vseh dežel brez strahu smeli izraziti svoja stališča in z njega tudi varno odšli, naj bi bili povsem nezdružljivi s katoliškim tolmačenjem omenjenih izrazov in $\mathrm{z}$ avtoritarnim pojasnilom, da se lahko protestanti udeležijo zbora zgolj, da bi slišali svojo obsodbo. V tem delu je vsekakor najzabavnejša implicitna grožnja, vpletena v navidez zaskrbljeno razmišljanje tajnika, ki ugotavlja, da bi se ob ponovnem sklicu zbora slabo podkovani papeški teologi, "večinoma sladokusci in užitkarji«, kaj slabo znašli v družbi veliko kompetentnejših protestantskih učenjakov. Še več, tudi ostali pravoverni škofje bi se na takem srečanju lahko okužili z njihovo boleznijo in jo raznesli na vse konce Evrope. Ponoven sklic koncila bi bil tako nadvse škodljiv za Rimsko cerkev.

$\mathrm{V}$ okviru terminološkega utemeljevanja tajnika je zanimiv predvsem izraz traditiones, ki se nanaša na cerkveno izročilo, kasnejše od Svetega pisma, in ga v tem kontekstu omenja tudi Dante v svoji Monarhiji (Alighieri [1313] 2013, 97). Seveda florentinski pesnik pojasni, da različni cerkveni odloki ne morejo biti pomembnejši od Svetega pisma, kar je tudi ena glavnih zahtev protestantov. Da je Vergerij ravno v tem času 
imel v rokah rokopis Monarhije, lahko sklepamo iz njegove grožnje inkvizitorjem leta 1554, češ da bo v kratkem poskrbel za prvo tiskano izdajo tega nevarnega Dantejevega dela. Poznal je tudi revolucionarno razpravo Marsilija Padovanskega $\mathrm{z}$ naslovom Defensor pacis, kar je razvidno iz razmišljanj o konciliarizmu, ki jih papeški tajnik nelagodno razgrinja pred Pavlom IV. Da gre za »strašno knjigo«, ki razglaša, da je koncil nad papežem, Vergerij pojasni že v svojem odzivu na seznam prepovedanih knjig iz leta 1549. Izjemna načitanost in poznavanje italijanske književnosti ter zgodovine sta bila Vergeriju vseskozi v veliko oporo in na tem področju je imel tisti čas bržkone malo enakovrednih sogovornikov.

Tudi druga razprava se začne $\mathrm{z}$ naslovom, ki ima občuten marsilijanski pridih: »Ali sme papež z orožjem in silo protestantom naložiti sklepe tridentinskega koncila«. Vseeno pa se kmalu izkaže, da je namen drugega govora predvsem neskromno razkazovanje dobrega poznavanja takratne evropske politike, s katero se je Vergerij do potankosti seznanil kot cerkveni diplomat. Tovrstni »zastraševalni« ekskurzi, zasnovani za zbijanje morale nasprotnika, so v njegovih spisih pogost pojav in se kot rdeča nit pojavljajo skozi njegovo pisanje ob različnih priložnostih in $\mathrm{v}$ različnih variacijah. Glavni namen druge razprave naj bi bil sicer prepričati papeža, da bi bilo kakršnokoli vojaško posredovanje proti protestantom nesmiselno, saj se je beseda evangelija že preveč razširila po evropskem severu, ki je za razliko od nestanovitnih zaveznikov Cerkve, torej cesarja, francoskega kralja in Benetk, trdno povezan v sovraštvu do vsega, kar je papeško in rimsko. Kljub bistroumni analizi, ki se v slogu Guicciardinija in italijanske historiografije Cinquecenta loteva celo psiholoških profilov vladarjev, pa se ni mogoče znebiti občutka, da se za kopico diplomatskih lekcij skriva predvsem avtorjeva zagrenjenost zavoljo propadle cerkvene kariere. To navsezadnje potrjuje tudi pokroviteljska sklepna misel, da naj Pavel IV., ki je dosegel že častitljivo starost, raje uživa svoja zadnja leta na udobnem in donosnem položaju in naj se raje kot vojni posveča obdarovanju svojih sorodnikov. Prav v tem blagohotnem nasvetu pa je seveda implicitno ponovno izražena cinična kri- 
tika nikodemitskih italijanskih prelatov, ki jim Vergerij nikoli ni mogel oprostiti njihove dvoličnosti.

Četudi bi se lahko upravičeno spraševali, kakšen učinek so imeli tovrstni nagovori na takratno ciljno publiko, pa lahko ugotovimo, da so Vergerijevi geopolitični ekskurzi za današnjega bralca nadvse zanimivi in poučni. S precejšnjo natančnostjo namreč že razkrivajo obrise zemljevida verskih vojn, ki so prizadele Evropo v naslednjih desetletjih, po drugi strani pa ponujajo privilegiran vpogled $v$ kompleksna razmerja moči znotraj Rimske cerkve, ki so krojila potek reformacije na italijanskih tleh.

Kot rečeno, so prvi izdaji knjižice, ki je anonimno izšla v Baslu leta 1556, kmalu sledili še trije ponatisi. Izdaja, ki je leto za tem izšla v Königsbergu, vsebuje tudi predgovor z Vergerijevim podpisom, iz česar gre sklepati, da je bila namenjena bralcem v severnih deželah, kjer Vergerijevo ime ni bilo omadeževano. Leta 1559 so v Augsburgu in Pforzheimu natisnili nekoliko razširjeni različici besedila, temu pa je Vergerij dodal še tretjo razpravo $\mathrm{z}$ naslovom »Sledi še tretji spis, ki dopolnjuje prejšnji dve poglavji in ugotavlja, da koncila ni mogoče ponovno obnoviti, papež pa nima tolikšne oblasti, da bi mogel sklepe s koncila s silo uveljaviti«. Na tretji spis Vergerij v svojem slogu opomni tudi avtorje Rimskega seznama prepovedanih knjig iz leta 1559, ko italijanske inkvizitorje, ne da bi razkril svoje avtorstvo, posmehljivo opomni, da so na seznam pozabili uvrstiti tudi tretji tajnikov nagovor:

Obsodili ste dva nagovora oziroma dopisa nekega tajnika papeža $\mathrm{Pa}$ vla IV., in kruto je, da niti tajnik ne more povedati svojega mnenja gospodarju med štirimi stenami, torej skorajda na uho, ne da bi ga spremenili v krivoverca, če ne govori na vaš način. Nemara pa menite, da je tako v imenu tajnika ali pod njegovo krinko govoril nekdo drug in vam kot s čopičem naslikal vse nevarnosti, ki vam pretijo, če ne boste dovolj previdni in bi nas hoteli jeziti. A kakorkoli naj si bodi, vas avtor opozarja, da morate popraviti naslov tako, da bo pisalo Actiones Secretarii tres, saj je letos dodal še en nagovor, lahko pa pogumno dodate tudi četrtega, ki bo kmalu zunaj. (Vergerio 1559, 13) 
Vergerij je tudi v času tretjega zasedanja koncila neutrudno grmel čez tridentinski cerkveni zbor. Da bi bil ponovno blizu dogajanja, se je leta 1561 vrnil v Graubünden, a mu tam zaradi sporov z vodji lokalnih cerkva niso bili več naklonjeni. Tudi sicer njegovi nagovori proti koncilu v Italiji niso več vzbudili zanimanja. Pred koncem svojega življenja je skušal izdati svoja zbrana dela v štirih zvezkih, a mu je leta 1563 uspelo na svetlo spraviti zgolj prvega $\mathrm{z}$ naslovom Primus tomus operum Vergerii adversus papatum, $\mathrm{v}$ katerem najdemo še enkrat vse Tri dopise papeškega tajnika skupaj. Čeprav je koncil, ki mu je posvetil toliko svojega časa in pisanja, preživel za skoraj dve leti, pa obljubljenega četrtega dopisa ni utegnil nikoli napisati.

\section{VIRI IN LITERATURA}

Alighieri, Dante. (s. d.) 2013. Monarhija. Prevod in spremna beseda Tomaž Jurca. Ljubljana: Slovenska Matica.

Cantimori, Delio. 1992. Eretici italiani del Cinquecento. Torino: Einaudi

Cavazza, Silvano. 2007. »Bonomo, Vergerij, Trubar«. Stati inu obstati 3 (5-6): 62-81.

---. 2013. "Nenavadna osebnost': Profil Petra Pavla Vergerija.» Stati inu obstati 9 (1718): $10-27$.

Jurca, Tomaž. 2016. »Inkvizitorjem po Italiji: Vergerijeva polemika proti piscem rimskega seznama prepovedanih knjig iz leta 1559.« Stati inu obstati 12 (23-24): 76-97.

Kerševan, Marko. 2015. »Peter Pavel Vergerij (1489-1565) in Fulvio Tomizza«. Stati inu obstati 11 (21-22): 295-317

Tomizza, Fulvio. (1984) 2015. Zlo pride s severa. Ljubljana: Beletrina.

Vergerij ml., Peter Pavel. (1556) 2018. Dopisi papeškega tajnika. Uredil in prevedel Gregor Pobežin. Ljubljana: Založba ZRC.

Vergerio, Pietro Paolo. 1559. A gl'inquisitori che sono per l'Italia: Del catalogo di libri eretici, stampato in Roma nell' anno presente. [Pforzheim].

https://doi.org/10.26493/2590-9754.14(28)209-218 